computed tomography showed that the size of the aneurysm was reduced. The patient's renal function recovered to preoperative levels after a transient use of hemodialysis. The patient was discharged from our hospital without blood-streaked sputum.

\section{Discussion}

The MK stent graft is a flexible, custom-made, curved stent graft. It usually takes a week until we receive the stent graft after placing an order. In this case the MK stent graft fit tightly to the 3-dimensional curvy portion of the aorta and did not cause kinking or endoleak at all. Although total replacement of the aortic arch would be one of the best solutions for the aortic arch aneurysm, this procedure is surgically stressful, especially for patients with complications. ${ }^{5}$ Advantages of endovascular stent graft delivery with extra-anatomic arch vessel bypass by SCP are relief from cardiac arrest, relief from circulatory arrest, and relief from use of an oxygenator. The preoperative creatinine clearance value of this patient was $18 \mathrm{~mL} / \mathrm{min}$, and the postoperative renal function recovered to preoperative levels after transient use of dialysis. This suggested that the level of surgical stress of this procedure was acceptable for this patient. SCP alone requires lower levels of heparinization than cardiopulmonary bypass because of the lack of an oxygenator. It is a big advantage of this procedure to prevent bleeding in a patient with such potential for massive lung bleeding. To reduce the risk of brain complications, we closed the arch vessels before the use of the side-biting clamp.

Endovascular delivery of the MK stent graft with extra-anatomic arch vessel bypass by using SCP could be a useful and minimally invasive therapeutic strategy for patients with aortic arch aneurysms who are considered at high surgical risk.

\section{References}

1. Dake MD, Miller DC, Mitchell RS, Semba CP, Moore KA, Sakai T. The "first generation" of endovascular stent-grafts for patients with aneurysms of the descending thoracic aorta. J Thorac Cardiovasc Surg. 1998;116:689-704.

2. Mitchell RS, Dake MD, Sembra CP, Fogarty TJ, Zarins CK, Liddel RP, et al. Endovascular stent-graft repair of thoracic aortic aneurysms. J Thorac Cardiovasc Surg. 1996;111:1054-62.

3. Orihashi K, Matsuura Y, Sueda T, Watari M, Okada K, Sugawara Y, et al. Echocardiography-assisted surgery in transaortic endovascular stent grafting: role of transesophageal echocardiography. J Thorac Cardiovasc Surg. 2000;120:672-8.

4. Kato M, Kaneko M, Kuratani T, Horiguchi K, Ikushima H, Ohnishi K. New operative method for distal aortic arch aneurysm: combined cervical branch bypass and endovascular stent-graft implantation. $J$ Thorac Cardiovasc Surg. 1999;117:832-4.

5. Coselli JS, Buket S, Djukanovic B. Aortic arch operation: current treatment and results. Ann Thorac Surg. 1995;59:19-27.

\title{
Does bridging to transplantation with a left ventricular assist device adversely affect posttransplantation survival? A comparative analysis of mechanical versus inotropic support
}

\author{
Jeffrey A. Morgan, MD, YooKyung Park, BS, Aftab R. Kherani, MD, Deon W. Vigilance, MD, Faisal H. Cheema, MD, \\ Mehmet C. Oz, MD, and Yoshifumi Naka, MD, PhD, New York, NY
}

I mplantation of a left ventricular assist device (LVAD) as a bridge to transplantation has become an acceptable intervention in patients with end-stage heart failure. ${ }^{1,2}$ Patients bridged to transplantation with LVADs have demonstrated improvements in blood pressure, hepatic function, renal function, physical function, and quality of life. ${ }^{3,4}$ However, whether mechanical support adversely affects posttransplantation survival is

\footnotetext{
From the Department of Surgery, Division of Cardiothoracic Surgery, College of Physicians and Surgeons, Columbia University, New York, NY.

Received for publication April 1, 2003; accepted for publication June 3, 2003.

Address for reprints: Yoshifumi Naka, MD, PhD, Columbia University, College of Physicians and Surgeons, 177 Fort Washington Ave, Milstein Hospital 7GN-435, New York, NY 10032 (E-mail: yn33@columbia.edu).

J Thorac Cardiovasc Surg 2003;126:1188-90

Copyright $\odot 2003$ by The American Association for Thoracic Surgery $0022-5223 / 2003 \$ 30.00+0$

doi:10.1016/S0022-5223(03)00935-8
}

still controversial. ${ }^{5}$ Do patients bridged to transplantation with an LVAD demonstrate decreased posttransplantation survival compared with patients bridged with inotropic support? The aim of this study was to answer this question.

\section{Patients and Methods}

We retrospectively reviewed our experience at Columbia Presbyterian Medical Center with bridge-to-transplantation patients from June 1996 through September 2002. During this time period, 266 patients in United Network for Organ Sharing status 1 were successfully bridged to transplantation by either mechanical ( $\mathrm{n}=$ $121,45.7 \%)$ or inotropic ( $\mathrm{n}=145,54.5 \%)$ support. LVAD support was provided by the HeartMate single-lead vented electric device (Thoratec, Pleasanton, Calif). Posttransplantation survival at 1, 3, and 5 years was evaluated in both groups.

Data were represented as frequency distributions and percentages. Values of continuous variables were expressed as means \pm SD. Continuous variables were compared by independent samples $t$ tests, whereas categorical variables were compared by $\chi^{2}$ tests. Kaplan-Meier analysis was used to calculate survival. Actuarial 
TABLE 1. Baseline clinical characteristics of patients

\begin{tabular}{lccc}
\hline Variable & LVAD & $\begin{array}{c}\text { Medical } \\
\text { therapy }\end{array}$ & $\boldsymbol{P}$ value \\
\hline $\begin{array}{l}\text { Mean age }(\mathrm{y}) \\
\text { Sex }\end{array}$ & $48.7 \pm 14.0^{*}$ & $52.6 \pm 13.6$ & $.023 \dagger$ \\
$\quad$ Male & $103(85.1) \ddagger$ & $106(73.1)$ & .017 \\
$\quad$ Female & $18(14.9)$ & $39(26.9)$ & \\
Race & & & \\
$\quad$ White & $88(72.7)$ & $102(70.3)$ & .668 \\
$\quad$ African American & $24(19.8)$ & $24(16.6)$ & .488 \\
$\quad$ Other & $9(7.4)$ & $19(13.1)$ & .134 \\
Cause of heart failure & & & \\
$\quad$ CAD & $54(44.6)$ & $58(40.0)$ & .425 \\
$\quad$ ICM & $61(50.4)$ & $76(52.4)$ & .774 \\
$\quad$ Other & $6(5.0)$ & $11(7.6)$ & .314 \\
\end{tabular}

$C A D$, Coronary artery disease; ICM, idiopathic cardiomyopathy.

${ }^{*}$ Mean \pm SD.

$\dagger P$ value from independent samples $t$ tests.

$\ddagger$ Absolute number (percentage).

survival at 1,3 , and 5 years after transplantation was calculated by constructing life tables. Significant risk factors for mortality were identified by multivariate Cox proportional hazard models. All data were analyzed with SPSS 11.5 software (SPSS Inc, Chicago, Ill).

\section{Results}

Demographics. Clinical demographics of patients in both groups are outlined in Table 1. Patients supported with LVADs were significantly younger than patients supported with inotropic therapy $(48.7 \pm 14.0$ years vs $52.6 \pm 13.6$ years, $P=.023)$. There were significantly more male patients in the LVAD group $(85.1 \%$ vs $73.1 \%, P=.017$ ). There was no significant difference in cause of heart failure between the groups.

Posttransplantation survival. Both groups demonstrated similar posttransplantation survival $(P=.649$, Figure 1$)$. Actuarial survival at 1,3 , and 5 years was $92.4 \%, 83.6 \%$, and $74.4 \%$, respectively, for the LVAD group, and $90.8 \%, 84.0 \%$, and $73.2 \%$, respectively, for the medical therapy group.

Risk factors for mortality. On the basis of univariate analysis, pretransplantation LVAD support was not a statistically significant risk factor for posttransplantation mortality $(P=$ .928). Sex was the only significant predictor of survival, with male patients demonstrating improved survival over that of female patients $(P<.001)$. Other variables evaluated included age $(P=.344)$, race $(P=.518$ for white patients, $P=.312$ for African American patients, and $P=.733$ for "other" patients), and cause of heart failure $(P=.807$ for coronary artery disease, $P=.790$ for idiopathic cardiomyopathy, and $P=.965$ for "other").

On the basis of multivariate analysis with Cox proportional hazard models, female sex was the only variable demonstrated to be a statistically significant risk factor for decreased posttransplantation survival (odds ratio, 3.518; 95\% confidence interval, 1.813-6.827; SE, 0.338; $P<$ $.001)$.

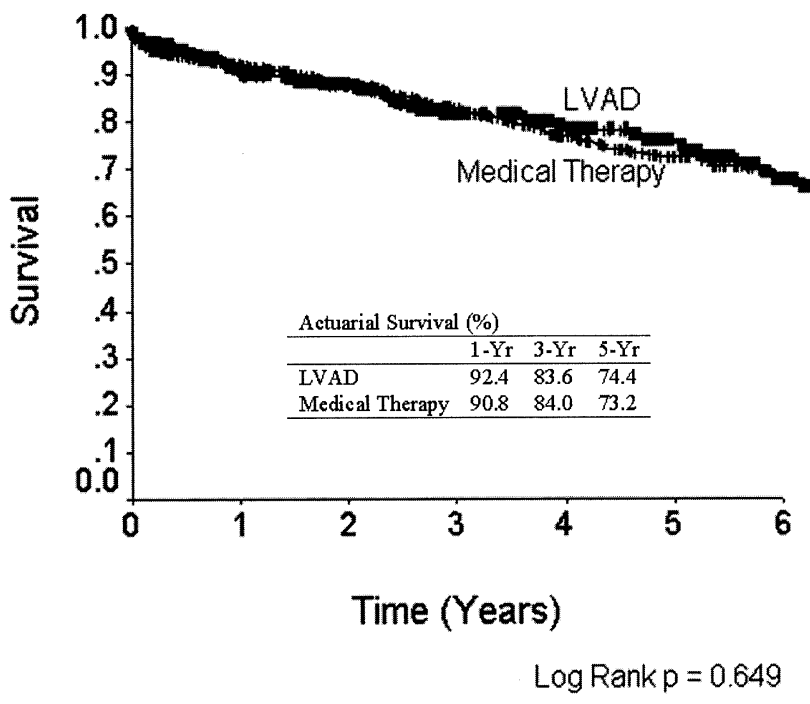

Figure 1. Actuarial posttransplantation survival for patients supported with LVADs versus medical therapy.

\section{Discussion}

In our study we demonstrated that patients bridged to transplantation with mechanical support had similar posttransplantation survival compared with that of United Network for Organ Sharing status 1 patients bridged with inotropic drugs. The HeartMate device, the first LVAD to gain US Food and Drug Administration approval for use as a bridge to transplantation, is the preferred device at our institution. It accommodates mobility, allowing patients to be discharged from the hospital and resulting in improved quality of life. It also obviates the need for anticoagulation. ${ }^{4}$

Limitations of this comparative study include that it was not a randomized study of LVAD versus inotropic therapy. LVADs were generally reserved for patients who had signs and symptoms of severe heart failure refractory to medical therapy. Therefore, patients supported with LVADs tended to manifest more severe clinical heart failure with a greater degree of instability than patients who were bridged to transplantation with inotropic drugs.

In conclusion, although the paradigm for assist devices might shift to a bridge to recovery or destination therapy, the role of an LVAD as a bridge to transplantation for patients with end-stage heart failure will remain an important one. At our institution, over the past 6 years, $71.2 \%(\mathrm{n}=121)$ of the 170 patients who underwent implantation of single-lead vented electric HeartMate devices as a bridge to transplantation were successfully bridged. LVADs permitted stabilization and optimization of patients with severe congestive heart failure without adversely affecting posttransplantation survival. ${ }^{3}$ A prospective randomized trial evaluating LVADs versus inotropic support for bridge-to-transplantation patients might be warranted to evaluate this issue more extensively. 


\section{References}

1. Pennington DG, McBride LR, Peigh PS, Miller LW, Swartz MT. Eight years' experience with bridging to cardiac transplantation. $J$ Thorac Cardiovasc Surg. 1994;107:472-81.

2. Peterze B, Lonn U, Jansson K, Rutberg H, Casimir-Ahn H, Nylander E. Long-term follow-up of patients treated with an implantable left ventricular assist device as an extended bridge to heart transplantation. J Heart Lung Transplant. 2002;21:604-7.

3. Bank AJ, Mir SH, Nguyen DQ, Bolman RM 3rd, Shumway SJ, Miller
LW, et al. Effects of left ventricular assist devices on outcomes in patients undergoing heart transplantation. Ann Thorac Surg. 2000;69: 1369-75.

4. Sun BC, Catanese KA, Spanier TB, Flannery MR, Gardocki MT, Marcus LS, et al. 100 long-term implantable left ventricular assist devices: the Columbia Presbyterian interim experience. Ann Thorac Surg. 1999;68:688-94.

5. Massad MG, McCarthy PM, Smedira NG, Cook DJ, Ratliff NB, Goormastic M, et al. Does successful bridging with the implantable left ventricular assist device affect cardiac transplantation outcome? J Thorac Cardiovasc Surg. 1996;112:1275-83.

\title{
Fifteen-month circulatory support for sustained ventricular fibrillation by left ventricular assist device
}

\author{
Motonobu Nishimura, MD, Masanori Ogiwara, MD, Masayuki Ishikawa, MD, Syogo Yatsu, MD, Ayumu Masuoka, MD, \\ Nobuyuki Okamura, MD, Kazuhito Imanaka, MD, Masaaki Kato, MD, Haruhiko Asano, MD, and Shunei Kyo, MD, \\ Saitama, Japan
}

$\mathrm{P}$ atients with end-stage heart failure who receive support from a left ventricular assist system (LVAS) have been shown to tolerate malignant ventricular arrhythmia fairly well. ${ }^{1,2}$ The duration of malignant arrhythmia in the previous reports was at most a little more than 10 days. This report describes a patient who has been in sustained ventricular fibrillation (VF) for more than 1 year and has been supported by an LVAS without showing any symptoms.

\section{Clinical Summary}

A 24-year-old woman, who demonstrated dilated cardiomyopathy, was first referred to us for heart failure and ventricular arrhythmia 5 years ago. At that time, she received the maximum medication and did well. She remained well until the age of 23 years, when she returned with profound heart failure and ventricular tachyarrhythmia resistant to medical therapy. Catecholamine was administered, and workup for cardiac transplantation was started. She experienced VF and was resuscitated using the percutaneous extracorporeal membrane oxygenator system (Emersave, Terumo, Tokyo, Japan). She was immediately brought to the operating room, where

From the Department of Cardiovascular Surgery, Saitama Medical School, Iruma-gun, Saitama, Japan.

Received for publication Feb 13, 2003; accepted for publication March 24, 2003.

Address for reprints: Motonobu Nishimura, MD, Department of Cardiovascular Surgery, Saitama Medical School, 38 Moro-hongo, Moroyama, Iruma-gun, Saitama 350-0495, Japan (E-mail: nishimur@ saitama-med. ac.jp).

J Thorac Cardiovasc Surg 2003;126:1190-2

Copyright $\odot 2003$ by The American Association for Thoracic Surgery $0022-5223 / 2003 \$ 30.00+0$

doi:10.1016/S0022-5223(03)00726-8 she underwent emergency placement of the Toyobo-NCVC LVAS (Toyobo, Osaka, Japan) with left ventricular drainage. Her postoperative course was essentially uneventful, but her ventricular arrhythmia continued despite aggressive antiarrhythmia medication. Three months after placement of the LVAS, she experienced VF again, which was resistant to external cardioversion (Figures $1 \mathrm{~A}$ and 1B). Although her heart had been fibrillated, her LVAS flow was almost unchanged (3-4 L/min), and she showed no symptoms. Despite all the attempts to restore her original rhythm, she remained in VF. After several days, we stopped the attempts because she had been well with no symptoms, and further attempts may have caused embolism as the result of intracardiac thrombus. Since then, her heart has been in sustained VF for 15 months, but she has been ambulated, like other patients supported by an LVAS, while awaiting heart transplantation (Figure 2). Although her right ventricle is not working, she has not demonstrated peripheral edema, pleural effusion, or ascites. Her pulmonary vascular resistance before LVAS placement was 2.44 Wood units. Her central venous pressure 3 months after demonstrating VF was approximately $10 \mathrm{~mm} \mathrm{Hg}$. Cardiac catheterization was not performed after sustained VF because of possible thrombus in her fibrillated heart.

\section{Discussion}

Sustained VF is not a lethal arrhythmia for patients supported by an LVAS. In a report by $\mathrm{Oz}$ and associates, ${ }^{1}$ an LVAS was successful in supporting 9 patients who continued to experience malignant ventricular arrhythmia during device support. The arrhythmias lasted from 10 minutes to 12 days. The patients reported weakness, but none reported syncope. Fasseas and coworkers ${ }^{3}$ reported the successful use of an LVAS for the management of refractory ventricular arrhythmia. Nonetheless, early electrical cardioversion is indicated in patients demonstrating sustained VF with LVAS support because usually there is more than a $1 \mathrm{~L} / \mathrm{min}$ decrease in device flow at the onset of $\mathrm{VF}^{1}$ 